A CASE OF

\title{
SOFTENING OF THE SPINAL MARROW
}

\author{
IN A BOY AFPECTED WITH CHOREA.
}

BY

ROBERT NAIRNE, M.D.

PGYSICIAN TO, AND LECTURER ON MRDICINE AT, ST. GRORGR'S hosPITAL.

Received November 12th.-Read November 26th, 1850.

As all facts which relate to disease in the Spinal Marrow may prove important in the elucidation of its physiology, I have thought that the history of the following case, and an account of the appearances found after death, might interest this Society.

George Strange, æt. 17, a greengrocer's boy, was admitted into St. George's Hospital on the 27th of June last. When I approached the sofa, on which he lay in the waiting room, and asked him to put out his tongue, I observed that he thrust it out in the same manner as a person with chorea. He had also the convulsive movements and distortion of features of chorea. His articulation was imperfect, but he had sufficient command over it to speak to me. He told me that he had pain in his back and knees and feet. He was unable to walk or even to stand. When he had been placed in bed I found that there was redness on his knees and ankles, as in rheumatism. His tongue was loaded, his skin was hot, and his pulse 108. On listening over the region of the heart $I$ ascertained that there was a mitral systolic murmur.

His relations informed me that he had suffered from 
rheumatism several times since the age of twelve, and that the last attack was about Christmas; but that this was the first time they had seen him "in this way." From Mr. James George of Kensington, under whose care he had been previous to his admission into the hospital, I afterwards learnt, that, "for the last five weeks the friends had observed an unsteady, jerking action in his hands, which prevented him from placing things quietly in their places. The last two weeks he stuttered much, and frequently contorted his mouth. On the 18th he complained of rheumatism; but felt better on the 22d, and went to market in a cart. On his return he complained of having had an unusual jolting. Up to this time he had been able to walk; but on the next day he kept his bed, and did not attempt to walk afterwards. The rheumatism, and chorea more especially, increased from this day. He was said to have had a fit on the morning of the 24th."

I treated him under the impression that he was suffering from an acute attack of rheumatism, which had brought on chorea. The following day he seemed better, his articulation was more perfect, and the convulsive movements less frequent. On the 29th, however, he was worse, redness appeared on his knuckles, and was no longer to be seen on his knees and feet. He had not slept since he had been in the house. On the 30th he became more restless, was delirious during the night, and on the 1st of July was evidently much worse. His features were more distorted, the pulse was weaker. The convulsive movements were more frequent, and so violent that the sides of his legs and body had become excoriated. During the last two days of his life he passed his motions under him. He died a little after midnight of the $3 \mathrm{~d}$, the convulsive movements having ceased some hours before his death, and as a state of coma came on.

The body was examined twelve hours after death. The contents of the spinal canal were first looked at. The spinal veins were distended with blood. A portion of the spinal marrow, an inch at least in length, and situated opposite the third and fourth dorsal vertebræ, was white, and so soft that 
the slightest pressure of the finger broke it up. It was almost in a fluid state. ${ }^{1}$ The whole thickness of this portion was in this state. In consistence, firmness, and colour, all the rest of the cord was strongly in contrast with this part. Within the cranium the sinuses of the dura mater and meningeal vessels were gorged with blood, and so also were the large veins distributed over the surface of the brain. The substance of the brain was firm throughout. Its cortical structure was darker than usual, and bloody puncta were very numerous in the medullary substance.

The pericardium was found adhering entirely to the heart. The left ventricle of the heart was firmly contracted; the other cavities contained very small coagula. On the auricular surface of the mitral valve, numerous minute small rounded excrescences presented themselves, giving a fringed appearance to the valve; the other valves were healthy. Both lungs were loaded with blood, and there were patches of extravasated blood in their most depending parts. There was nothing unusual observed in the cavity of the abdomen.

This case is an additional instance of the frequent occurrence of chorea in rheumatism or in those of a rheumatic diathesis, to which attention has been of late years directed: But in Strange there was also palsy of the lower limbs. When he was admitted into the hospital, the inability to walk and the pain in the back I considered to be owing to rheumatism; but no doubt these symptoms were connected with the disease of the spinal marrow, the existence of which was revealed after death.

There are four instances recorded of softening of the spinal marrow in persons previously affected with chorea. Ollivier d'Angers quotes one as related by Brera, and two as having occurred to Guersent ; but, he adds, “ $j$ 'ai eu l'occasion d'ouvrir sous ses yeux le rachis d'un enfant qui était également affecté

1 In the central part of this softened portion of the spinal marrow there was fluid, and the remainder was so thoroughly disorganised that it was thought unnecessary to put any of it under the microscope. 
de chorée, chez lequel la moelle épinière n'offrit aucune altération sensible : sa consistance, sa couleur, et celle de ses membranes étaient dans l'état naturel; c'est ce qu'on observe le plus souvent." The fourth case is recorded by Dr. Keir, of Moscow. ${ }^{2}$ The history of the boy's symptoms, who had had chorea for three years, and the report of his state seven days only previous to his death, "walks about daily for some time without assistance," is a proof that the softening could not have been in the relation to this disease of cause and effect. I would observe, moreover, that the result generally noticed of organic alteration of nervous structure is palsy, and not spasm.

When we examine the facts which morbid anatomy has accumulated, we find that there is no condition of diseased structure which has been constantly discovered in chorea. Nor do I think that what has been observed in the brain and spinal cord, in such cases, affords any proof that chorea originates in either one or the other. In support of this conclusion I will add the result of what $I$ have observed in the practice of St. George's Hospital. Besides Strange, I have seen three other patients with chorea who have died there. In all, a careful examination was made of the contents within the cranium and spinal canal. One was under my own care, and two were patients of Dr. Macleod. In all, there was congestion of the vessels of the brain. In my own patient there was congestion of the vertebral veins and of the substance of the spinal cord. In the first one, which occurred in the practice of Dr. Macleod, the posterior veins of the spinal cord were rather more than usually distended with blood, but there was no alteration in the appearance of the spinal marrow itself. It was also found perfectly healthy in the second case, though the veins of the cord were much congested. But the state of congestion in the vessels of the brain and spinal marrow, which was observed in these three cases, is of very frequent occurrence where the convulsions

1 Traité de la Moelle Epinière, 2 ${ }^{\text {re }}$ ed., tom. ii, p. 817.

2 Edin. Medical and Surgical Journal, vol. xliii, p. 93. 
of chorea have not been exhibited. They are seen, for example, very generally in the bodies of persons who have died in various forms of fevers. Enough, I think, has been adduced to show that the pathology of chorea is not to be explained by the morbid anatomy of the brain or spinal marrow. Clinical observations of the disease and study of its symptoms, of the various causes in which it originates, and of its wonderful mental phases, will give us a truer insight into its nature. Contemplating it under all the circumstances with which it is connected, I am inclined to agree with my colleague, Dr. Wilson, that "chorea is more than merely nervous," that it is a disorder of the entire system, and does not proceed specially from the nerve, though expressed principally by the muscle."1

The softening of the spinal marrow, in this case, cannot, I conceive, be considered otherwise than as an accidental occurrence viewed in relation to chorea. Here arises, however, an interesting inquiry. It will be remembered that palsy ensued in the lower limbs of George Strange, but that he felt pain in them. Moreover, as often as any one approached Strange's bed, and still more manifestly when a question was put to him, the convulsive movements of the voluntary muscles were increased, not only in the face and upper part of the body, but even more violently in the lower limbs, and below that portion of the spinal marrow in which disease was going on to complete disintegration. The structure of a considerable portion of the spinal cord appeared to be altogether destroyed through its entire thickness, and, according to the usual teaching in physiology, incapable of the office of conducting nervous impressions. Yet the voluntary muscles of the palsied half of the body were excited to increased convulsive action by the influence of emotion.

We are taught that there should be a perfect state of the spinal cord, in order that an impression may be conveyed from the brain to the spinal nerves. We are also told that

${ }^{1}$ On Spasm, Languor, and Palsy, p. 101. 
42 DR. NAIRNE ON SOFTENING OF THE SPINAL MARROW.

the seat of emotion is in the mesocephale. If these be true propositions, I would ask through what channel were the impressions conveyed to the voluntary muscles in Strange's palsied lower limbs, when they were thrown into convulsive movements under emotional excitement? I confess that I find no satisfactory answer to this question; and this case seems to me to prove that there is yet much for us to learn respecting the functions of the spinal marrow. 